\title{
PUBLIC HEALTH CRISIS IN WAR AND CONFLICT - HEALTH SECURITY IN AGGREGATE
}

\author{
John Quinn ${ }^{1}$, Tomáš Zelený2, ${ }^{3}$, Rammika Subramaniam ${ }^{1}$, Vladimír Bencko² \\ ${ }_{1}^{1}$ Prague Centre for Global Health, Institute of Hygiene and Epidemiology, First Faculty of Medicine, Charles University, Prague, Czech Republic \\ ${ }^{2}$ Institute of Hygiene and Epidemiology, First Faculty of Medicine, Charles University, Prague, Czech Republic \\ ${ }^{3}$ Institute of Economic Studies, Faculty of Social Sciences, Charles University, Prague, Czech Republic
}

\section{SUMMARY}

Objective: Public health status of populations is multifactorial and besides other factors it is linked to war and conflict. Public health crisis can erupt when states go to war or are invaded; health security may be reduced for affected populations.

Methods: This study reviews in aggregate multiple indices of human security, human development and legitimacy of the state in order to describe a predictable global health portrait.

Results: Paradigm shift of large global powers to that non-state actors and proxies impact regional influence through scaled conflict and present major global health challenges for policy makers. Small scale conflict with large scale violence threatens health security for at-risk populations.

Conclusion: The paper concludes that health security is directly proportional to state security.

Key words: fragile and failed states, public health, non-communicable disease, infectious disease, global health, health security

Address for correspondence: J. Quinn, Prague Centre for Global Health, Institute of Hygiene and Epidemiology, First Faculty of Medicine, Charles University, Studničkova 7, 12000 Prague 2, Czech Republic. E-mail: john.quinn@lf1.cuni.cz

https://doi.org/10.21101/cejph.a4455

\section{INTRODUCTION}

Health security is directly proportional to state sovereignty, legitimacy and mandate to provide health services $(1,2)$. Health security is negatively impacted across fragile and failed states while regional conflicts intensify and manifest globally (3). The connections between violence and health are difficult to study and many approach considerations have been applied within this research. This aggregate research through core measures of country status and multiple development indices in public health and health indicators provides rigorous information as to how much the general indices relate to tangible health security. We explain that by proxy, health security is implemented by incidence of preventable disease.

Aggregate research describes data combined from several measurements, such as those related to health security and multifaceted concepts of conflict and health. Based on this aggregate research model and at the individual level of health, it is observed that health behaviours and outcomes have multi-level determinants and can be predictable $(4,5)$. The perspective of multi-level analysis acknowledges the importance of both individual and environmental variables in determining health behaviours and outcomes at the level of the indivisible unit and conceptualizing multiple levels of organization relevant to a particular research question and the individual (6).

\section{MATERIALS AND METHODS}

This research model implements aggregate analysis with spread data constructing a model by merging disease (chol- era, tuberculosis, malaria, and measles) into a single variable "agreg”, which is a simple sum of cumulative incidence. Incidence can be described as a rather rough variable to implement in such an analysis as attributes of disease used in the aggregate analysis are extremely diverse. These ailments affect different populations globally and are widely dissimilar in general but are preventable.

Statistically however, generality is not lost due to disease burden; public health infrastructure and prevention programmes aimed at mitigating these diseases when following best practices are similar in nature. For example, measles, cholera and TB are preventable through vaccination, albeit with varying seroconversion and efficacy rates, and malaria is preventable through primary prevention measures (chemoprophylaxis, mosquito bed nets and sprays, prompt diagnosis and initiation of effective therapy). Diagnosis of these diseases can be performed clinically or through bedside diagnostic procedures. However, these diseases can be difficult and expensive for poorly resourced public health infrastructures to prevent and treat.

Finally, measles, cholera, tuberculosis, and malaria are endemic in much of the resource poor and developing world; these regions are where fragile and failed states originate and thrive. Thus, an argument that populations are or would be indifferent about getting these diseases is rejected. This variable is the proxy for health security, as a high risk of exposure to deadly infectious diseases is a prime example of inadequate health security and the variable itself is not interdependent with other variables (indices implemented with this research do not have incidence of infectious diseases included), which allows for clear statistical analysis. All statistical analyses were processed by R program. 
The multiple indices used in this analysis involve high-level data composed of a multitude and combination of individual data. By combining multiple indices with data sets for economic, health, social and behavioural, political, security, and overall health status, this aggregate research concludes on human health trends from the data that indicate health status - the health security environment or portrait.

\section{Failed States Index}

The US Fund for Peace publishes the annual Failed States Index (FSI) listing those countries who are failed states or in great risk of failure. There are multiple metrics that rely on key social, political and economic indicators that compose this index. The reason for inclusion of this index into the aggregate analysis is that the included diseases are preventable through vaccination programmes promoted by state health ministries and departments, as well as through basic public health and hygiene measures (clean water, access to night-time mosquito nets or repellents, immunization and educational programmes, etc.) based upon health security infrastructure promoted by organized, transparent and properly funded state health institutions.

Humanitarian aid programmes are great but can be very inconsistent, have difficult successes that are not reproducible and are under donor strain given global social, political and environmental complex emergencies; oftentimes, strong state institutions may have been a better alternative when possible than just sending short lived aid $(7,8)$. The assumption and expectation in using the FSI for this aggregate analysis is that states in the absence of or decreased exposure to conflict and war will be stronger states, will not be fragile or failing states and will promote health security for the population (correlating with an assumed lower incidence of measles, cholera, tuberculosis, and malaria).

\section{State Fragility Index}

The State Fragility Index (SFi) combines scores measuring two essential qualities of state performance: effectiveness and legitimacy. These two quality indices combine scores on distinct measures of the key performance dimensions of security, governance, economics, and social development. The SFi utilizes a set of eight indicators in order to measure state fragility in previous years and examines changes in each indicator over time (9). The SFi helps look at state fragility overall.

\section{Public Integrity Index}

The Public Integrity Index (PII) is a more focused index which captures on the quality of state-granted institutions in the given country. The difference between this index and the rest is that this one is not focused on the population per se, but solely rates the quality of institutions that are provided within the country (10). In terms of this paper this is almost a key index, because it is very focused and comes from a different methodology, which allows it to function as a control to the other, global in nature, indices.

\section{Political Instability Index}

The Political Instability Index (PI) defines political instability as the propensity of a government collapse (11), upon which is originally estimated a model in which political instability and economic growth are jointly determined. In our paper, we continue upon the index as it connects the economic nature of states with its stability. In our analysis, the index functions as second control, which is more focused and does therefore counter-balance the otherwise global indices.

\section{Human Security Index}

The Human Security Index (HSI) covers 232 countries and societies, and is not intended to become an annual index for publication but rather is a result of over 25 years of indicator development. Steady advances in characterizing different aspects of the human condition have resulted in indicators, covering increasing numbers of countries, on a wide variety of subjects; the HSI is an attempt to create an index on people-centric Human Security (12). Components of the HSI include data from the Economic Fabric Index (EFI), Environmental Fabric Index (EnFI) and the Social Fabric Index (SFI). In sum, the HSI can be considered as an index of 30+ leading economic, environmental and social indicators related to health and state stability (12).

\section{Economic Fabric Index}

The Economic Fabric Index (EFI) uses Gross Domestic Product (GDP) per capita, adjusted for pricing; purchasing power parity (PPP), a theoretical exchange rate as opposed to the real one. Purchasing power parity attempts to eliminate the fluctuations in observed exchange rates by recalculating the exchange rate using a standard basket of goods, thus making comparisons of prices across different countries much more accurate in terms of real value), equality of income distribution (income and finance distribution); and financial-economic governance, which is described as the risk of hardship through unsustainable trade or debt, or from catastrophic health care governance disaster. The EFI is implemented in this aggregate analysis for economic status of the population and is the reason not to include GDP per capita alone, as it is of much bigger interest when combined with other main economic factors, especially income distribution, than as a standalone variable. Economic security is directly linked to health security.

\section{Environmental Fabric Index}

The Environmental Fabric Index (EnFI) uses environmental vulnerability, environmental protection (access to clean water, etc.), policies and deliverables, and overall environmental sustainability in a population. The Environmental Fabric Index blends risk of environmental disasters, environmentally healthy living conditions, environmental sustainability and governance (13). This index basically ranks the studied countries in terms of the results of state action in the area of environment and directly connected factors. The EnFI is the main variable that contains environmental information for the HSI.

\section{Social Fabric Index}

The Social Fabric Index (SFI) lists health education and information empowerment, protection of, and benefits from, diversity and peacefulness governance, including protection from official 
or illegal corrupt practices and food security (12). In its essence, the SFI ranks the country in terms of those social factors, which are a direct result of state activities. This is very powerful as the information in this combined index is much more valuable as it captures a descriptive side of society.

\section{Literacy Rate}

Literacy Rate (LR) is the percentage of people who are literate in a given country. The importance of this factor is indirect - it is expected that a more literate population would be able to get better information about the prevention of disease (especially measles, cholera, tuberculosis, and malaria), as well as educate itself about health promotion in general for the family unit, and would be able to demand health security promotion and measures in the form of policy from state institutions and empowerment. An illiterate population increases public health risk and may be linked to poor health security status and state fragility.

\section{Life Expectancy at Birth}

This variable serves for comparison of results. The comparison of results as to how much do the indices explain the incidence of preventable lethal diseases and how much they explain the actual life expectancy. In global health, policy and resources are devoted to reducing the incidence, duration and severity of major diseases that cause morbidity but not always that of mortality, and to reducing their negative impact on human life (14). Infant mortality and ensuring political crisis is not proposed to be linked, however, infant mortality is a better indicator for democracies prone to failure than it is for less democratic states, as well as an indication of maternal health security $(15,16)$. It is important to capture both fatal and non-fatal health outcomes in a summary measure of average levels of population health. Healthy life expectancy (HALE) at birth adds up expectation of life for different health states, adjusted for severity distribution making it sensitive to changes over time or differences between countries in the severity distribution of healthy states (17).

\section{Preventable Illness and Infectious Disease}

Conflict and war are inextricably linked to human disease and deterioration in health security $(1,2,18-20)$. Many infectious disease are preventable through vaccination, simple prevention measures and basic access to standardized primary health care. Measles, cholera and tuberculosis (TB) have been selected as leading infectious diseases to find linkages to that of health security reduction in conflict areas. Routine measles vaccination for children, combined with mass immunization campaigns in countries with low routine coverage, is a key public health strategy to reduce global measles deaths $(21,22)$. More than 20 million people are affected by measles each year (21). The cholera disease burden is estimated at 3 to 5 million cases and 100,000-120,000 deaths due to cholera every year and approximately 80 percent of cases can be successfully treated with oral rehydration salts and even prevented via vaccine (14). Areas with low sanitation and no potable water due to war and conflict are at increased risk of cholera. It is estimated that approximately one third of the world's population is infected with TB, that there are 8 to 9 million new cases of TB and nearly 2 million deaths from TB each year (22). Globally, malaria is the most important parasitic disease that threatens health security annually.

\section{RESULTS}

The analysis of the data is done through a two stage least squares (2SLS) method where it is instrumented by the Failed States Index and by the Social Fabric Index. The reason is that the FSI is rather a general observation index and thus it is expected to be correlated with any variable that is not put into the equation making it in the residual. However, the SFI is very highly correlated with FSI and is a rather restricted index, so to assume that its correlation with non-included variables is non-existent or at least very small as their relationship would be highly indirect. For most variables, observations for different years are not identified; the only data available are in a cross-sectional format. In order to counter heteroscedasticity, White robust residuals are implemented.

For the 2SLS estimation, first the FSI is estimated by the SFI. The results are shown in Table 1.

To answer the initial question, the most natural testing method is a simple linear regression in the following form where the Social Fabric Index and Failed States Index together form the instrumental variable for FSI (IVFSI):

\section{agreg $=\alpha+\beta * I V F S I+\varepsilon \quad$ (equation 1$)$}

This trivial method gives the FSI as a significant ( $\mathrm{p}$-value $<0.001$ ) variable for explaining the incidence of preventable infectious diseases. But, the overall explanatory power seems rather limited as the coefficient of determination is only 0.10 . In order to get a more practical answer, an extended model is implemented. The model takes the following form:

agreg $=\beta_{0}+\beta_{1} * I V F S I+\beta_{2}{ }^{*} P I+\beta_{3} * G I+\beta_{4}{ }^{*} E F I+\beta_{5} * E n F I+\varepsilon$ (equation 2)

Instead of the Human Security Index (HSI), the main three parts are used - the Economic Fabric Index, Environmental Fabric Index and the Social Fabric Index. The Social Fabric Index is, however, already being used for FSI instrumenting, so it is not used in the estimation by itself. The model estimation results are shown in Table 2.

The explanatory power of the model has improved significantly to 0.2253 . While that is still not high, given the size and variance of the examined sample, it is significant. More intriguing are the specific results themselves - the FSI and Political Instability Index turned out to be completely insignificant with respect to the dependent variable, while the Public Integrity Index takes over as the main explanatory variable.

The Economic Fabric Index and Environmental Fabric Index are also fairly significant, but surprisingly at a rather lower level, yet their coefficients have a level higher coefficient compared

Table 1. Linear regression with White robust residuals. Dependent variable $=$ FSI

\begin{tabular}{|c|c|c|c|c|}
\hline Variable & Coefficient & $\begin{array}{c}\text { Standard } \\
\text { error }\end{array}$ & t-statistic & $\mathbf{p}$ \\
\hline Constant & 164.64 & 3.78 & 43.51 & $<0.001$ \\
\hline SFI & -159.93 & 5.86 & 43.51 & $<0.001$ \\
\hline
\end{tabular}

$N=83 ; R^{2}=0.90 ;$ Root MSE = 7.44; $F(1,81)=743.79 ; p<0.001$ 
Table 2. Linear regression with White robust residuals. Dependent variable $=$ agreg

\begin{tabular}{|c|c|c|c|c|}
\hline Variable & Coefficient & $\begin{array}{c}\text { Standard } \\
\text { error }\end{array}$ & t-statistic & $\mathbf{p}$ \\
\hline Constant & $16,509.01$ & $5,476.25$ & 3.01 & 0.003 \\
\hline IVFSI & 2.68 & 25.52 & 0.11 & 0.916 \\
\hline $\mathrm{PI}$ & -167.65 & 64.60 & -2.59 & 0.011 \\
\hline $\mathrm{PII}$ & -36.25 & 73.51 & -0.49 & 0.623 \\
\hline $\mathrm{EFI}$ & $-10,629.49$ & $7,259.81$ & -1.46 & 0.147 \\
\hline $\mathrm{EnFI}$ & $-10,941.05$ & $7,046.88$ & -1.55 & 0.125 \\
\hline $\mathrm{N}=141 ; \mathrm{R}^{2}=0.25 ;$
\end{tabular}

$\mathrm{N}=141 ; \mathrm{R}^{2}=0.25 ;$ Root MSE $=5161.9 ; \mathrm{F}(4,136)=8.72 ; \mathrm{p}<0.001$

to the other variables, suggesting their potential impact may be much higher. This means that the Failed States Index on a global scale is rather unable to explain incidence of infectious diseases, which may be against conventional expectations. The model also provides a prompt explanation - the FSI does contain mostly government stability themed components.

With the Political Instability Index itself being irrelevant, the FSI takes over the insignificance as well. The problem is much more technical than social, as the results suggest what truly matters is the ability to take actions through strong, transparent and accountable institutions through evidenced based policy implementation, for as long as the institutions necessary for such a move exist and are operational, the remainder of the public sector status of the state is irrelevant. The higher magnitude factors are population income and environmental conditions, the former is the obvious indicator of whether people can prevent the contamination by infectious diseases by themselves while the latter is a good indicator of likelihood of contracting the disease given the environmental condition. So, while the external conflict or in general political instability may have an adverse effect on the creation of necessary policy institutions, the institutions themselves and fundamental factors (economic and environmental conditions) play the major role in infectious disease prevention, and possibly in ensuring health security for populations.

The main issue of the previous model is that health security is not only the incidence of preventable infectious diseases, but includes many other factors. Thus, these results reflect only a part of the portrait. So, in order to solidify these results, the same model is made but with a wider dependent variable, one which includes health security and, unfortunately, many more variables. The average result of the smaller and larger model should then be a more accurate result than that of any single of those models. For the dependent variable life expectancy (LE) is used. The model calculation is seen below:

$$
\begin{aligned}
l e= & \beta_{0}+\beta_{1} * I V F S I+\beta_{2} * P I+\beta_{3} * P I I+\beta_{4} * E F I+\beta_{5} * E n F I \\
& +\beta_{6} * \text { agreg }+\varepsilon \quad \text { (equation 3) }
\end{aligned}
$$

The results of its estimation are shown in Table 3.

The results are quite different from the previous case. The Failed State Index is very significant in this model with life expectancy decreasing in increasing values of FSI, much as would be predicted. The Public Integrity Index has remained around the top of the explanatory variables as it is still highly significant. The Environmental and Economic Fabric Indices no longer share the same importance - the Economic Fabric Index is almost six
Table 3. Linear regression with White robust residuals. Dependent variable $=L E$

\begin{tabular}{|c|c|c|c|c|}
\hline Variable & Coefficient & $\begin{array}{c}\text { Standard } \\
\text { Error }\end{array}$ & t-statistic & $\mathbf{p}$ \\
\hline Constant & 35.61 & 6.43 & 5.54 & $<0.001$ \\
\hline IVFSI & -0.18 & 0.04 & -4.12 & $<0.001$ \\
\hline $\mathrm{PI}$ & 0.21 & 0.11 & 1.94 & 0.056 \\
\hline $\mathrm{PII}$ & 0.07 & 0.15 & 0.44 & 0.662 \\
\hline $\mathrm{EFI}$ & 23.61 & 10.21 & 2.31 & $<0.001$ \\
\hline EnFI & 3.91 & 6.80 & 0.58 & 0.567 \\
\hline Agreg & 0.00 & 0.00 & -2.77 & 0.007 \\
\hline
\end{tabular}

$\mathrm{N}=83 ; \mathrm{R}^{2}=0.69 ;$ Root MSE = 5.41; F(6, 76) = 35.65; $\mathrm{p}<0.001$

times as much impactful in scale as the Environmental Fabric Index, which has lost importance in this model and has become barely significant.

As for scale, since the FSI is approximately 100 times larger in units than the EFI and EnFI, it has about the same effect on life expectancy as the level of income, only in the opposite direction. The economic situation of a country or population has then about twice as much impact as these other variables. Finally, the coefficient of determination is up to 0.6907 , which is more than double that of the previous model. That suggests that there is much less unexplained variance than in the previous case, which is both expected and important as it should be the case that aggregate variables (in our case the indices) are better at explaining other aggregate variables than concrete ones.

Comparing the results of both models, they fit perfectly. For the Economic and Environmental Fabric Indices, we made a case for health security to be well instrumented by incidence of preventable infectious diseases. Their switching roles when it comes to diseases and life expectancy is perfectly logical, because life expectancy requires significantly more factors which are influenced rather by an individual's income than prevention of infectious disease. Furthermore, life expectancy has more factors involved that are more important than the environment alone. Avoiding mosquitoes and other infectious but preventable illness from birth in sub-Saharan Africa is extremely difficult, but an individual can extend a life through healthy lifestyle, including access to nutritious and abundant food, and when having access to quality primary health care and disease prevention in general - this is the environment that engenders health security.

\section{CONCLUSION}

This aggregate research has reviewed indices and variables related to public health in countries that are in crisis and thus fragile to the point where some could be marked as failed states. However, the FSI used to measure the quality of national level institutions does not capture all variables related to state fragility and health. The explanation is provided by the Economic and Environmental Fabric Indices. They both have a very large impact on the incidence of preventable infectious diseases and give a new context to the issues faced by the state in providing an environment for health security. 
The matter is split into two levels - the primary cause and the resolution of effects. The primary cause seems to be the quality of the environment, which greatly reduces the incidence of preventable infectious diseases. In parallel, there is a nationwide issue of improving the quality of the environment that is rather impossible at an individual level. Environmental policy is difficult to tackle even in terms of a single state as the environment is rather global in nature, resulting in poor health effects from a bad transborder environment. On the other hand, what is capable of mitigating the problems caused by poor environment is personal wealth (which is captured by the Economic Fabric Index as its main component is income per capita). Indeed, economic security can and in significant amount of cases does dictate health security.

To summarize, the data suggest that to improve health security in fragile and failed states, policy focus should seek to resuscitate fragile states, mitigate the loss of failed states, provide health security in the form of prevention, prevent environmental degradation, and engender economic security improving environmental conditions that affect health. It also suggests that empowering the population in terms of personal freedom and wealth greatly increases the ability of a population to counter the impacts of poor environmental conditions by itself.

\section{Limitations}

The Failed State Index is contested as a good aggregate to review the listed variables. Some opponent researchers describe the index as deficient, stating the index to be counterproductive to states as diverse as Colombia, Malawi, Somalia, Iraq, Haiti, and Tajikistan with data in aggregate. The main points of contention with the FSI relate to the inability to distinguish capacity gaps, security gaps, and legitimacy gaps that states experience; and that these gaps often do not coincide in a given country, and the logical responses to each of the three gaps diverge in significant ways (23). Lastly, HIV/AIDS status and associated data were not directly used in this analysis as health indicators due to the disproportionate geographical representation and disease burden.

\section{Acknowledgements}

The authors acknowledge their thanks to the First Faculty of Medicine, Charles University in Prague and to the Institute of Economic Studies at Faculty of Social Sciences of Charles University in Prague for their support of our study by the grants GAUK 1254213 and PRVOUK- P28/1LF/6.

\section{Conflict of Interests}

None declared

\section{REFERENCES}

1. Quinn J, Martins N, Cunha M, Higuchi M, Murphy D, Bencko V. Fragile states, infectious disease and health security: the case for Timor-Leste. J Hum Secur. 2014;10(1):14-31. doi: 10.12924/johs2014.10010014.
2. Quinn J, Zeleny T, Bencko V. Food is security: the nexus of health security in fragile and failed states. Food Nutr Sci. 2014 Oct;5(19):1828-42.

3. Williams P. Violent non-state actors and national and international security. ISN Case Study Series. International Relations and Security Network (ISN); 2008.

4. Marshall MG. Global report on conflict, governance, and state fragility series - fragility, instability and the failure of states: assessing sources of systemic risk. A CPA Working Paper. Council on Foreign Relations; 2008.

5. Von Korff M, Koepsell T, Curry S, Diehr P. Multi-level analysis in epidemiologic research on health behaviours and outcomes. Am J Epidemiol. 1992;135(10):1077-82.

6. Diez-Roux A. Ecologic variables, ecologic studies, and multilevel studies in public health research. In: Detels R: Oxford textbook of public health. Oxford: Oxford Univerzity Press; 2009.

7. Hughes C. Dependent communities: aid and politics in Cambodia and East Timor. Ithaca and New York, USA: Cornell University Press; 2009.

8. Moyo D. Dead Aid: why aid is not working and how there is a better way for Africa. New York: Farrar, Straus and Giroux, LLC; 2009.

9. Marshall MG, Cole BR. Global Report 2011: conflict, governance, and state fragility. Vienna: Center for Systemic Peace; 2011.

10. Zartman IW. Cowardly lions: missed opportunities to prevent deadly conflict and state collapse. London, UK: Lynne Rienner Publishers; 2005.

11. Kekic L. The economist intelligence unit's index of democracy [Internet]. Democracy Index. The World in 2007 [cited 2016 Aug 11]. Available from: http://www.economist.com/media/pdf/DEMOCRACY_INDEX 2007 v3.pdf.

12. Hastings DA. Describing the human condition - from human development to human security: an environmental Remote Sensing and GIS approach. In: Proceedings of the International Symposium on Geoinformatics for Spatial Infrastructure Development in Earth and Allied Sciences (GISIDEAS); 2008 Dec 4-6; Hanoi, Vietnam.

13. Alesina A, Ozler S, Roubini N, Swagel P. Political instability and economic growth. J Econ Growth. 1996;1(2):189-11.

14. DeLaet DL, DeLaet DE. Global health in the 21st century: the globalization of disease and wellness. Routledge; 2015.

15. Rotberg RI. When states fail: causes and consequences. Princeton, USA: Princeton University Press; 2004.

16. Deen J, von Seidlein L, Clemens JD. Issues and challenges of publichealth research in developing countries. In: Farrar J, Hotez P, Junghanss T, Kang G, Lalloo D, White NJ, editors. Manson's tropical diseases. 23rd ed. Elsevier; 2014. p. 40-8.

17. Helman GB, Ratner SR. Saving failed states: how the United Nations let countries fall apart, and how it needs to adapt if it wants to put them back together. Foreign Policy. 1992-1993;89:3-20.

18. Lyon $P$. The rise and fall and possible revival of international trusteeship. Journal of Commonwealth and Comparative Politics. 1993;31(1):96-110.

19. Ottaway M, Mair S. States at risk and failed states - putting security first. Democracy \& Rule of Law Project. German Institute for International and Security Affairs, Carnegie Endowment for International Peace; 2004.

20. Centers for Disease Control and Prevention (CDC). Measles - United States, 2000. MMWR Morb Mortal Wkly Rep. 2002 Feb 15;51(6):120-3.

21. Peltola H, Heinonen OP, Valle M, Paunio M, Virtanen M, Karanko V, et al. The elimination of indigenous measles, mumps, and rubella from Finland by a 12-year, two-dose vaccination program. N Engl J Med. 1994 Nov 24;331(21):1397-402.

22. Corbett EL, Watt CJ, Walker N, Maher D, Williams BG, Raviglione MC, et al. The growing burden of tuberculosis: global trends and interactions with the HIV epidemic. Arch Intern Med. 2003 May 12;163(9):1009-21. 